\title{
Experimental research on dynamic imbibition of fractured heavy oil reservoir under different temperatures
}

\author{
Yongge Liu $\cdot$ Huiqing Liu $\cdot$ Qing Wang \\ Zewei Zang $\cdot$ Jingwen Cui $\cdot$ Zhaohui Lv
}

Received: 7 May 2013/Accepted: 28 August 2013/Published online: 15 September 2013

(C) The Author(s) 2013. This article is published with open access at Springerlink.com

\begin{abstract}
Fractured reservoirs contain a large fraction of the world supply of oil and imbibition is one of the dominant recovery mechanisms. For fractured reservoirs containing heavy oils or tars, oil viscosity is high and it is hard to get a good development effect at reservoir temperature. However, if thermal methods are adopted, the oil viscosity will decrease sharply as temperature goes on and the oil recovery will increase on the contrary due to capillary imbibition. In this paper, fracture is created by wrapping the core with a steel wire mesh. Before flooding, cores are let to stand at the experimental temperature to eliminate the effect of thermal expansion on oil recovery. Considering that oil volume recovered is very small, a high precision electronic balance is used to weigh the oil and then calculate the oil volume. Different factors including contact area, matrix permeability, oil viscosity, water injection rate, temperature of the injected fluid and wettability of the core are all investigated. Results of this work should be helpful for the better understanding of the capillary imbibition in the development of fractured heavy oil reservoir.
\end{abstract}

Keywords Dynamic imbibition - Fracture $\cdot$ Heavy oil reservoir - Experimental research $\cdot$ Influence factor

\section{Introduction}

Fractured porous media are usually divided into matrix and fracture systems. The matrix contains most of the oil storage but has low permeability. On the contrary, fractures

Y. Liu $(\bowtie) \cdot$ H. Liu · Q. Wang · Z. Zang · J. Cui · Z. Lv MOE Key Laboratory of Petroleum Engineering, China University of Petroleum, Beijing, China e-mail: yg.leo@foxmail.com contain little oil but have high permeability (Rangel-German and Kovscek 2002). Due to the significant difference between matrix and fractures, if imbibition is weak and no stimulation method is taken, oil in the matrix is hardly to be recovered and the reservoir will suffer a big recovery loss. Therefore, similar to common heavy oil reservoirs, thermal methods are required to enhance oil recovery for fractured reservoirs containing heavy oils or tars (Sumnu and Aziz 1996; Sumnu 1996). In October 1977, Lacq Superieur oil field located in the southwest of France was developed by steam injection, and this was the first successful case for the development of fractured heavy oil reservoir by thermal method (Bernard and Jerome 1982). In China, Caogu first block of Shengli oil field and the ninth block of Karamay oil field are also successfully developed by steam injection (Lin et al. 2000; Yuan et al. 2005; Wang et al. 2004). Regarding the recovery mechanisms of fractured heavy oil reservoirs, many researchers have taken experimental or mathematical methods to simulate the developing process and relative publications are available. To sum up, the main mechanisms in the development of fractured heavy oil reservoir by thermal methods mainly include thermal expansion, capillary imbibition, gas generation, gravity drainage, chemical reaction, alternation of the rock matrix, distillation, solution gas drive and rock compaction, etc. (Mollaei and Maini 2010; Penney et al. 2005). Among these mechanisms, imbibition, which means that the wetting phase (water) infiltrates into the matrix and displaces the non-wetting phase (oil) out, plays an importance role (Mattax and Kyte 1962; Mehran and Abbas 2000). For heavy oil reservoirs, the viscous force is much larger than capillary force at the initial reservoir temperature. Therefore, the imbibition effect is weak or even does not occur by cold water flooding. However, oil viscosity is highly sensitive to temperature so the viscous force decreases 


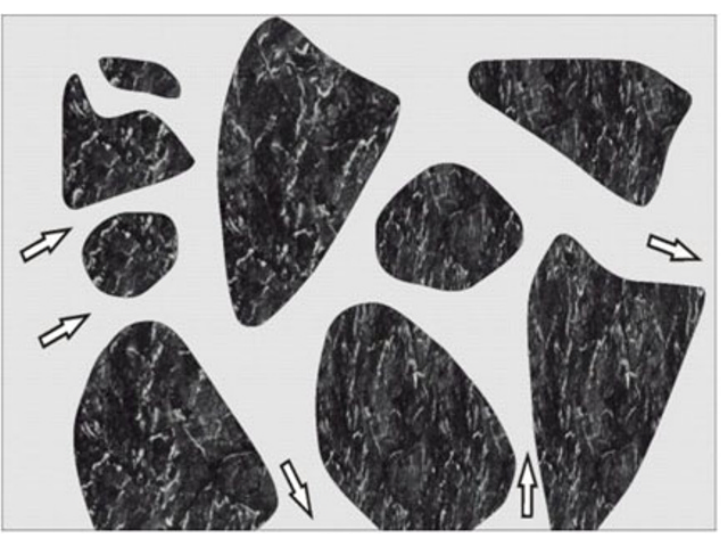

(a)

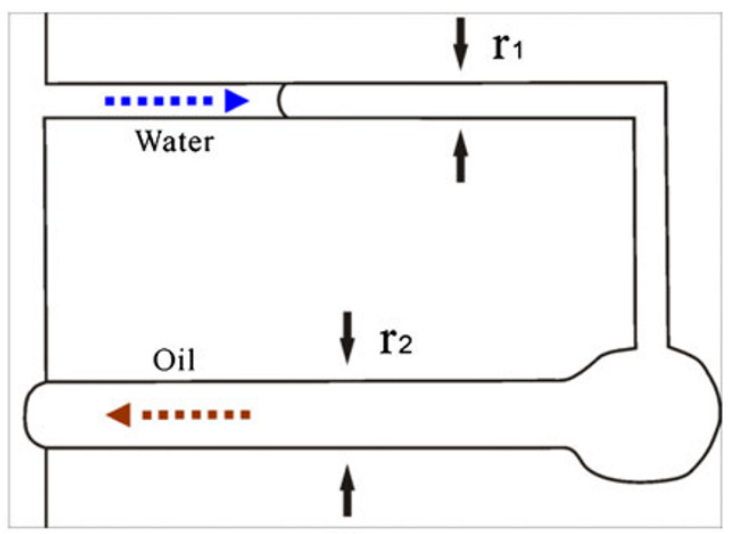

(b)

Fig. 1 Schematic plot of imbibition: a imbibition of core, $\mathbf{b}$ simplified imbibition of core

significantly and more oil is recovered by imbibition after thermal methods are applied. Oil expulsion from capillary imbibition varies with recoveries ranging from a few percent to as high as $70 \%$ (Mollaei and Maini 2010).

Referring to influence factors of imbibition, abundant researchers have taken static method to investigate the influence of core properties, fluid properties, etc., on the imbibition effect. However, the development of reservoir is a flooding process so dynamic imbibition simulation is more close to the real case compared with static simulation. In this paper, a basic theory of imbibition is first introduced and then the influences of contact area, matrix permeability, oil viscosity, water injection rate, temperature of the injected fluid and wettability of the core on the dynamic imbibition are all investigated by laboratory experiments. Relative results and conclusions should be helpful for the better understanding of the capillary imbibition in the development of fractured heavy oil reservoir.

\section{Basic theory of imbibition}

The driving force of imbibition is capillary force which can be expressed by

$P_{\mathrm{c}}=\frac{2 \sigma \cos \theta}{r}$

where $P_{\mathrm{c}}$ is the capillary force, $\sigma$ the interfacial tension, $\theta$ the contact angle, and $r$ is the radius of pore.

Figure 1 is the schematic plot of imbibition. For real core, the sizes of pores and throats are not the same. According to Eq. (1), pores and throats with smaller sizes create bigger capillary force compared with those with larger sizes. So for water-wet core, under this differential pressure, water will penetrate into the pores and throats with smaller sizes and displace oil out first. Along with the increase in water saturation, the sizes of pores and throats through which water enters become larger and the capillary force decreases correspondingly. Finally, the capillary force balances the resistant force and thus imbibition stops (Jishan 2006).

In the fractured heavy oil reservoir, at the initial temperature, oil viscosity is too high. Imbibition is hard or even does not occur if no measures are taken. However, viscosity is highly sensitive to temperature. Therefore, if hot water or steam is injected, the viscosity decreases sharply and oil flows easily. Meanwhile, the core becomes more water-wet at higher temperatures and the capillary force increases with temperature which has been called "thermally augmented imbibition" (Mollaei and Maini 2010). Besides temperature, many factors including the matrix permeability, fluid injection rate, development degree of the fracture, etc., also have an influence on imbibition.

\section{Experiment preparations}

Selection of oil and water samples

Three kinds of oil samples are used in the experiments. The viscosity-temperature relationships of the samples, which are measured by rotational viscometer Brookfield-II (Fig. 2), are listed in Table 1. The samples labeled S1 and S2 are from Henan oil field (Henan Province, Sinopec, China) and the third sample labeled S3 is from Jilin oil field (Jilin Province, Petrochina, China). Distilled water is used in core flooding experiments. Densities of oil and water samples under different temperatures are measured by digital density meter DMA45 (Fig. 3), and the results are listed in Table 2. 


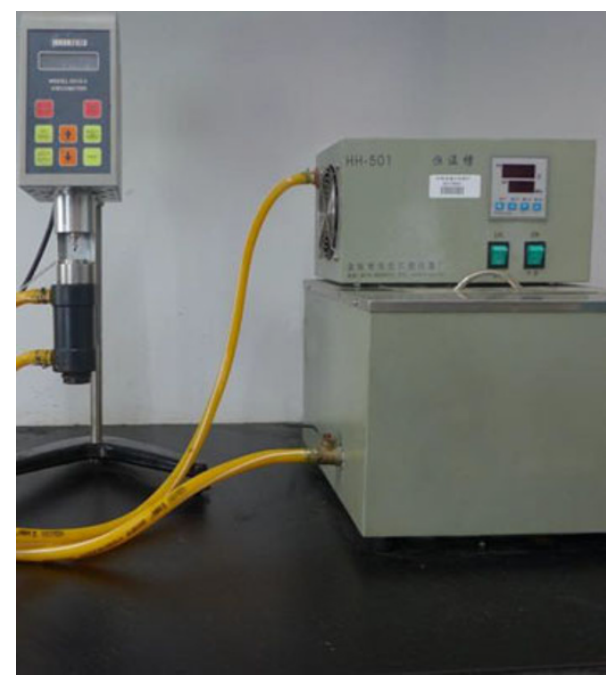

Fig. 2 Viscometer Brookfield-II

Selection of core samples

Table 1 Viscosity-temperature characteristics of crude oil samples

\begin{tabular}{llll}
\hline Temperature $\left({ }^{\circ} \mathrm{C}\right)$ & \multicolumn{4}{l}{ Viscosity $(\mathrm{mPa} \mathrm{s})$} \\
\cline { 2 - 4 } & $\mathrm{S} 1$ & $\mathrm{~S} 2$ & $\mathrm{~S} 3$ \\
\hline 26.5 & - & - & 7,640 \\
26.9 & - & 1,310 & - \\
29.8 & 258.8 & - & - \\
40.0 & 121.9 & 422.5 & 2,140 \\
50.0 & 66.6 & 198.8 & 878.1 \\
60.0 & 39.8 & 111.3 & 453.1 \\
70.0 & 26.1 & 64.3 & 251.3 \\
80.0 & 17.8 & 42.8 & 160.9 \\
90.0 & 12.9 & 29.1 & 91.9 \\
\hline
\end{tabular}

The water-wet core samples used (shown in Fig. 4a) are taken from yellow sandstone outcrop from Sichuan Province of China and the oil-wet core samples (shown in Fig. 4b) are man-made and produced by Daqing oil field company. Relative basic parameters of the cores are listed in Table 3.

As shown in Table 3, the permeabilities of water-wet cores labeled A-1 to A-5 and oil-wet core B-1 are kept at the same level and permeabilities to water are about $80 \times 10^{-3} \mu \mathrm{m}^{2}$. The permeabilities of the remaining cores are much lower and permeabilities to water are about $20 \times 10^{-3} \mu \mathrm{m}^{2}$.

\section{Selection of experimental apparatus}

Figure 5 shows the flowchart of the dynamic imbibition experiment. ISCO pump with a precision of $0.00001 \mathrm{ml} / \mathrm{min}$ is chosen as the displacement apparatus. Pressure changes

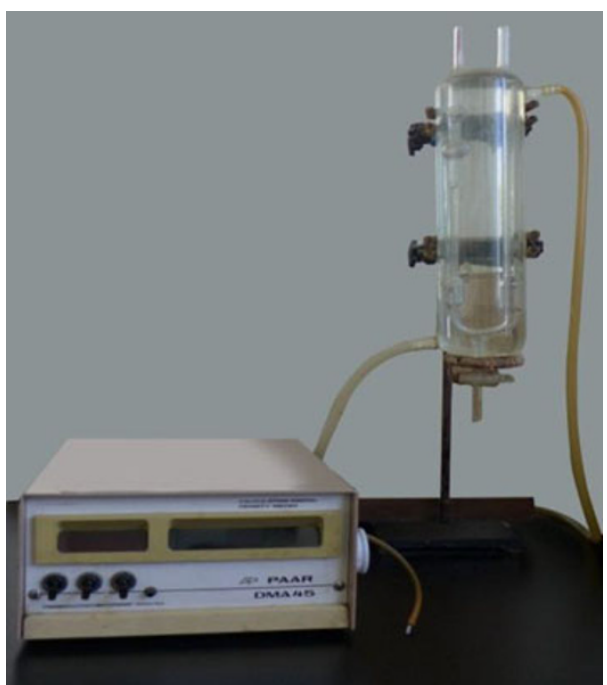

Fig. 3 Digital density meter DMA45

Table 2 Relationship between densities and temperatures of experimental samples

\begin{tabular}{llll}
\hline Samples & \multicolumn{3}{l}{ Density $\left(\mathrm{g} / \mathrm{cm}^{3}\right)$} \\
\cline { 2 - 4 } & $30{ }^{\circ} \mathrm{C}$ & $60{ }^{\circ} \mathrm{C}$ & $90{ }^{\circ} \mathrm{C}$ \\
\hline $\mathrm{S} 1$ & 0.8503 & 0.8251 & 0.8073 \\
S2 & 0.9349 & 0.9068 & 0.8871 \\
S3 & 0.9523 & 0.9233 & 0.9032 \\
Distilled water & 0.9962 & 0.9838 & 0.9747 \\
\hline
\end{tabular}

during the experiment are automatically recorded by computer through pressure sensors. The highest temperature and precision which the thermostat can provide are 150 and $0.1{ }^{\circ} \mathrm{C}$, respectively. Confinement pressure is imposed by the hand pump during the experiment and the value is $5 \mathrm{MPa}$.

From Table 3, we can see that the length of core is about $5 \mathrm{~cm}$ and the pore volume is about $4 \mathrm{ml}$. In view of the oil saturation and recovery, the final recovered oil volume is generally less than $2 \mathrm{ml}$. Therefore, if cylinder is used to measure the recovered oil volume, many problems including visual errors, uneven oil-water contact, etc., may occur. Therefore, in this paper, the weighing method is taken to measure the produced oil. First, place the measuring cylinder which contains the produced fluid (water and oil) in the thermostat $\left(70{ }^{\circ} \mathrm{C}\right)$ and dry for a long time to guarantee that all water have been evaporated. Then, weigh the measuring cylinder which only contains oil and record the value. Finally, wash the measuring cylinder and weigh the cylinder again. The difference between the two records is the weight of oil. Combing with oil densities listed in Table 2, the volume of oil produced by imbibition is 
Fig. 4 Photograph of core samples: a water-wet cores, b oil-wet cores

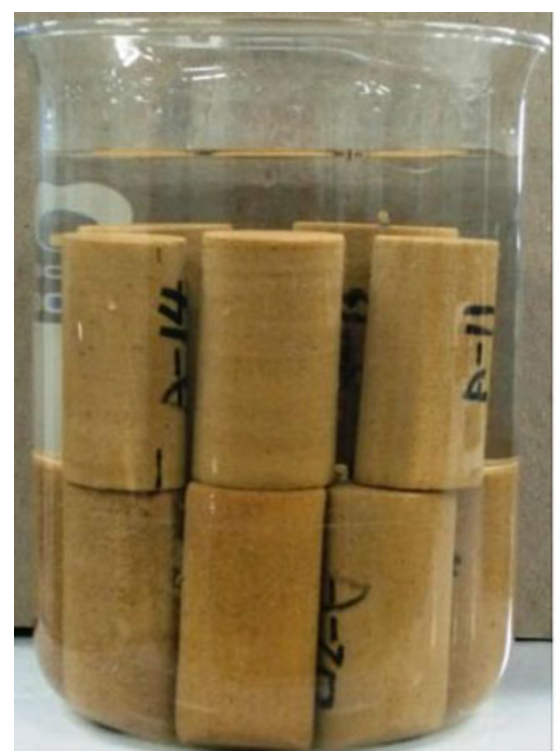

(a)

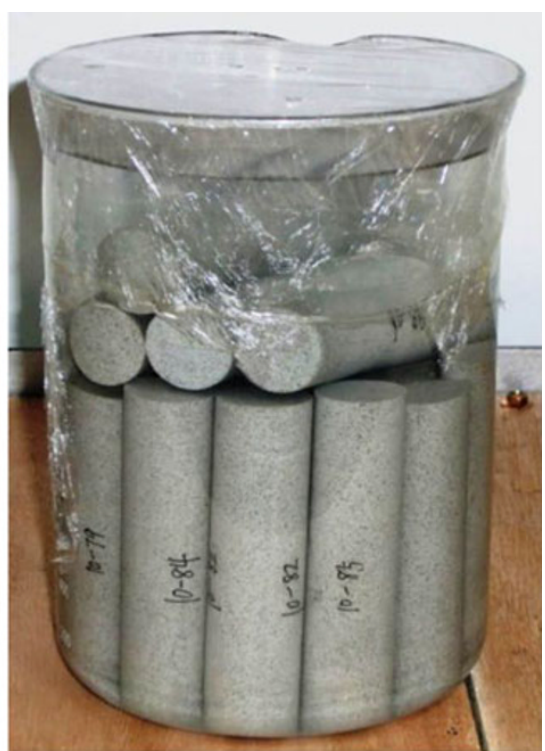

(b)
Table 3 The basic parameters of the cores

\begin{tabular}{lllllll}
\hline No. & $\begin{array}{l}\text { Length } \\
(\mathrm{cm})\end{array}$ & $\begin{array}{l}\text { Diameter } \\
(\mathrm{cm})\end{array}$ & $\begin{array}{l}\text { Porosity } \\
(\%)\end{array}$ & $\begin{array}{l}\text { Permeability to water } \\
\left(10^{-3} \mu \mathrm{m}^{2}\right)\end{array}$ & $\begin{array}{l}\text { Initial water } \\
\text { saturation }(\%)\end{array}$ & Wettability \\
\hline A-1 & 5.014 & 2.514 & 15.87 & 80.50 & 23.03 & Water-wet \\
A-2 & 5.010 & 2.520 & 16.96 & 77.60 & 18.17 & Water-wet \\
A-3 & 4.994 & 2.510 & 16.67 & 82.30 & 24.13 & Water-wet \\
A-4 & 4.918 & 2.502 & 16.58 & 75.90 & 16.12 & Water-wet \\
A-5 & 5.018 & 2.510 & 17.51 & 81.20 & 28.72 & Water-wet \\
A-6 & 5.000 & 2.534 & 14.69 & 19.60 & 27.22 & Water-wet \\
A-7 & 5.040 & 2.536 & 14.47 & 17.80 & 21.77 & Water-wet \\
A-8 & 5.008 & 2.540 & 16.27 & 18.60 & 22.46 & Water-wet \\
A-9 & 5.032 & 2.536 & 16.94 & 20.10 & 28.48 & Water-wet \\
A-10 & 4.980 & 2.540 & 16.28 & 21.30 & 29.07 & Water-wet \\
A-11 & 5.020 & 2.534 & 15.72 & 18.90 & 20.57 & Water-wet \\
A-12 & 5.000 & 2.540 & 16.02 & 21.00 & 19.88 & Water-wet \\
A-13 & 5.018 & 2.540 & 16.35 & 19.50 & 27.93 & Water-wet \\
A-14 & 5.030 & 2.540 & 16.16 & 20.40 & 26.64 & Water-wet \\
A-15 & 4.992 & 2.530 & 14.91 & 21.20 & 27.65 & Water-wet \\
A-16 & 5.011 & 2.540 & 15.83 & 19.20 & 12.66 & Water-wet \\
B-1 & 5.015 & 2.537 & 15.93 & 76.1 & & Oil-wet \\
\hline
\end{tabular}

obtained. However, one problem existing in this method is that the oil produced may have a mass loss during the drying process. Considering this, three oil samples with different masses are taken into three beakers and dried for $24 \mathrm{~h}$ at $70{ }^{\circ} \mathrm{C}$. During this process, the mass of the samples are measured for several times and relating data are plotted in Fig. 6. From this figure, we can see that the masses of the three samples nearly have no change. By calculation, the maximum mass loss is only $0.1 \%$. So, we can just assume that the mass loss during the drying process is negligible and the weighing method is reliable.

\section{Experimental studies on the influential factors of imbibition recovery}

Influence of contact area on imbibition recovery

By adjusting the width of the mesh

The oil sample labeled S1 and the cores labeled A-3 and A-4 are used to accomplish the experiment. Fluid injection rate is set to $0.05 \mathrm{ml} / \mathrm{min}$. Figure 7 shows the mesh wrapped core. As shown in this figure, if there is no mesh, 
Fig. 5 Flowchart of dynamic imbibition experiments

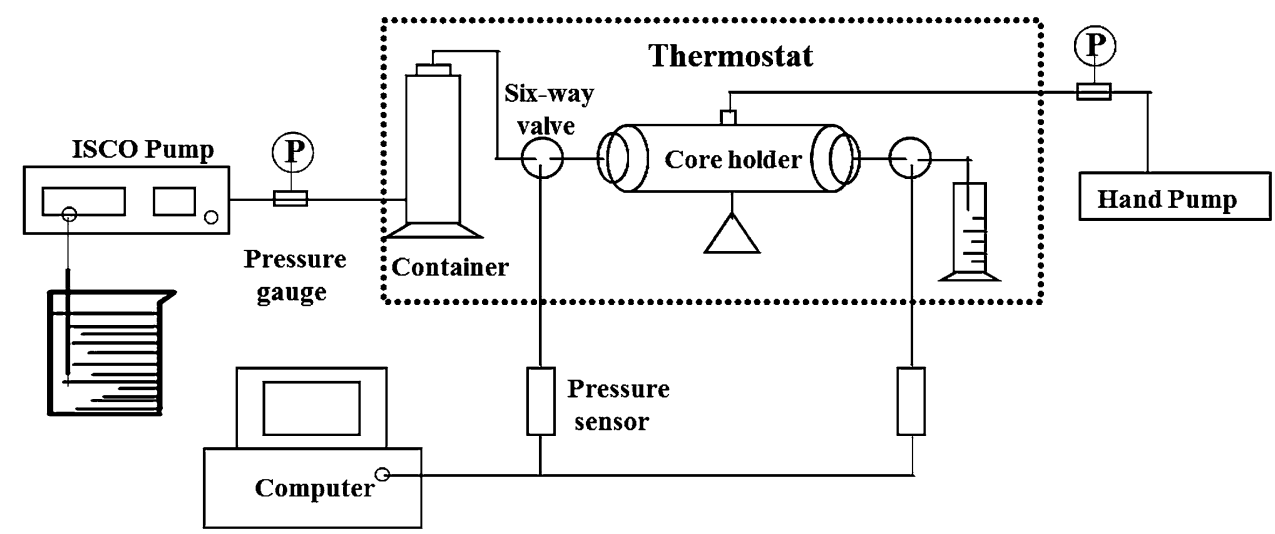

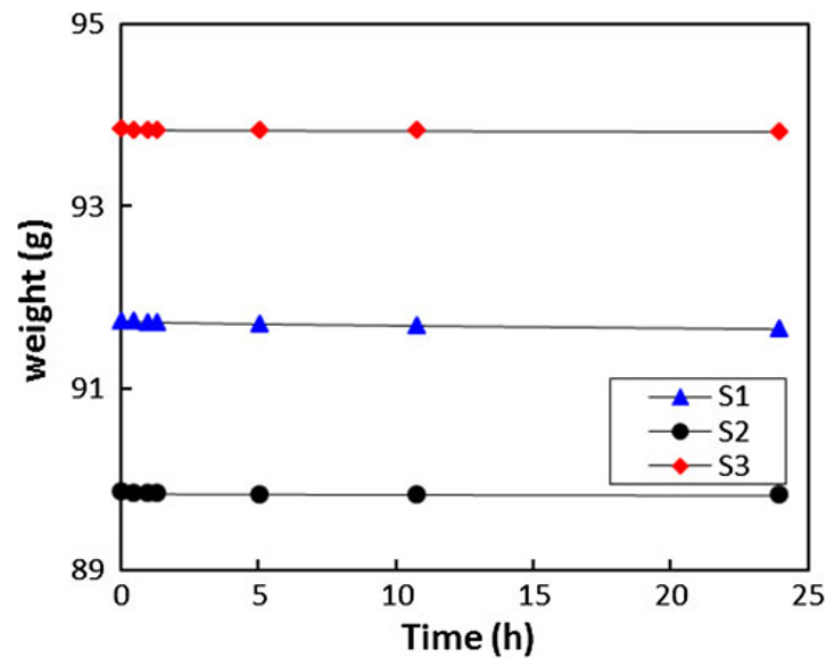

Fig. 6 Mass changes with time of three oil samples

under the confinement pressure, the rubber in the core holder will guarantee that no fluid flows through the side of the core. However, if the mesh exists, the injected water will flow through the mesh and this is one way to approximately simulate fracture. As shown in Fig. 7, the length of the mesh is equal to that of the core different contact areas can be simulated by adjusting the width of the mesh. The experiments are done under three different temperatures including 21 (room temperature), 60 and $90{ }^{\circ} \mathrm{C}$. In order to eliminate the disturbance of thermal expansion on the final oil recovery, before increasing temperature, it is required to let the core stand in the thermostat with temperature equal to the next experimental temperature for a long time. Figure 8 shows the comparison of recoveries and oil recovery rates when the widths of the mesh equal 1 and $3 \mathrm{~cm}$.

From Fig. 8a, we can see that both curves show the same trend. Temperature has a great impact on the dynamic capillary imbibition. At $21^{\circ} \mathrm{C}$, oil viscosity is so high that the viscous force is much bigger than capillary force and imbibition does not occur (no oil is produced). However, when temperature is increased to $60{ }^{\circ} \mathrm{C}$, the oil recovery improves significantly. This is because on one hand, oil viscosity is highly sensitive to temperature after the increase of temperature, the oil viscosity decreases by a big margin. On the other hand, the core becomes more waterwet due to the increase of temperature the imbibition effect becomes more significant. When temperature is increased to $90{ }^{\circ} \mathrm{C}$, oil recoveries rise again but the amplitudes of the growths are limited due to the high recovery at $60{ }^{\circ} \mathrm{C}$. Comparison of the recovery rate curves shows that the contact area has great influence on imbibition recovery. The core with big contact area has a much higher oil rate at the initial stage when imbibition occurs. However, the high oil rate only lasts for a short time; after that, it decreases

Fig. 7 Mesh wrapped core

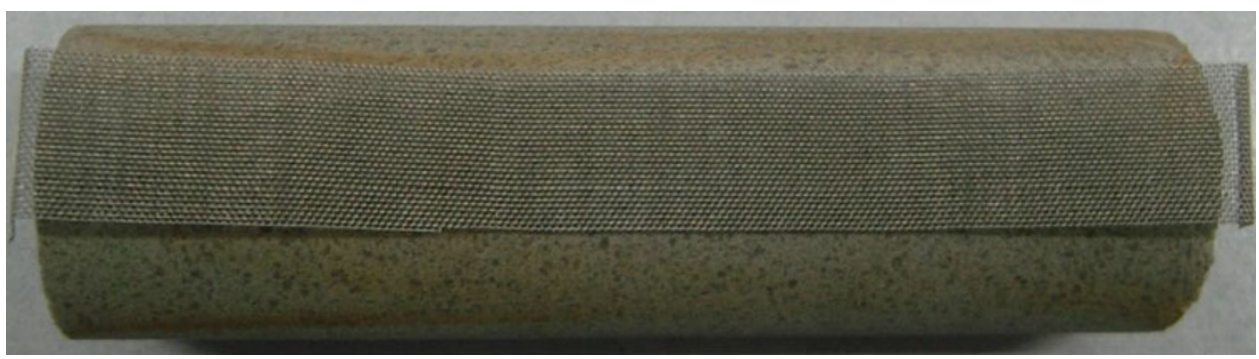




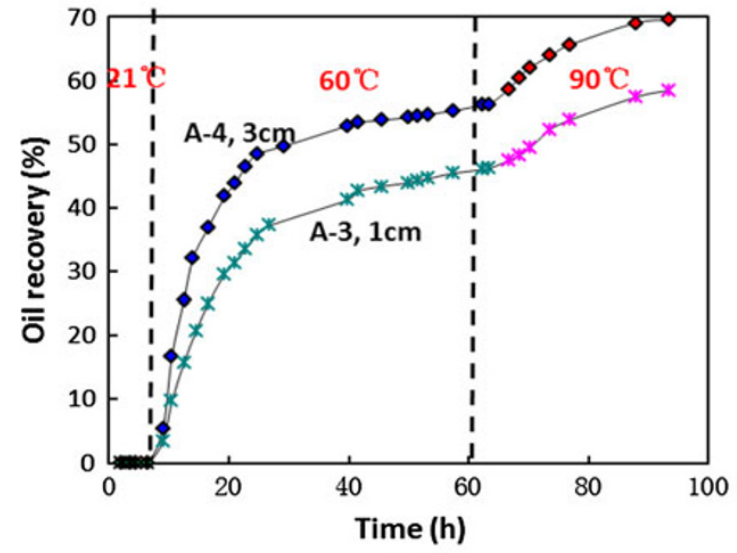

(a)

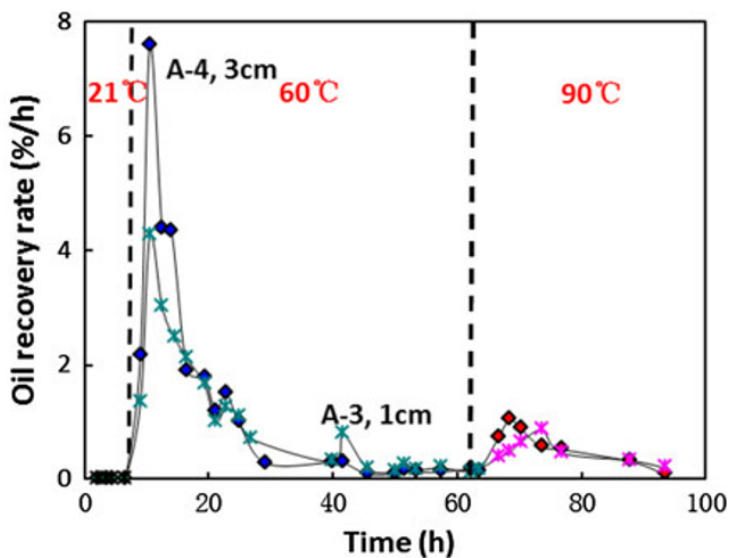

(b)

Fig. 8 Comparison of recoveries and recovery rates of cores with different mesh widths: a recovery curves, b recovery rate curves

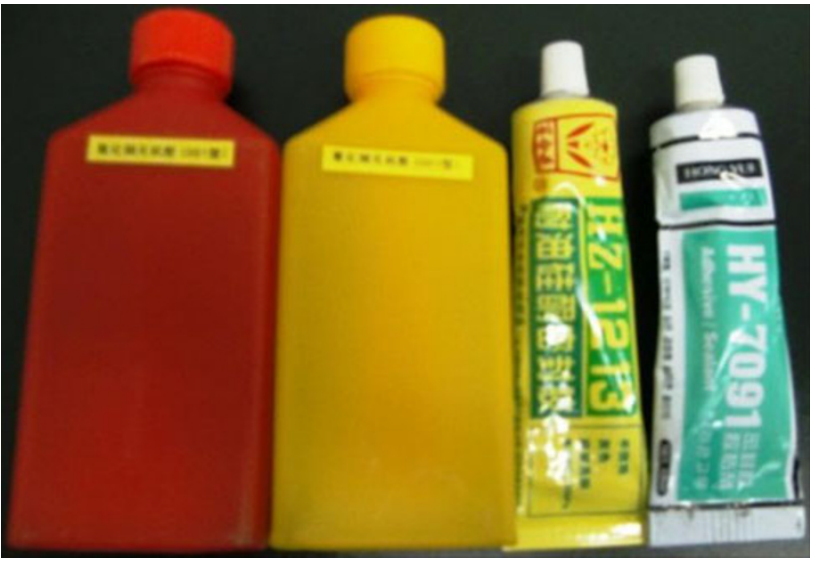

Fig. 9 Photo of different kinds of glues

sharply and the two curves tend to overlap. So, we can conclude that big contact area is helpful to the increase of oil recovery and this improvement is mainly due to the high oil rate at the initial stage when imbibition occurs.

\section{By plugging the both ends of the core}

Considering that the experiment is conducted under high temperatures, a high-temperature resisting glue is needed to plug the ends of the core. Figure 9 shows the three kinds of glue available. As shown in this figure, the left two bottles contain CPS copper oxide. Upon use, the chemicals in the two bottles are mixed according to the fixed proportion and then high-strength glue will be created. The third and fourth bottles contain silicone sealant and the common heatresisting glue, respectively. In order to examine and compare the high-temperature resisting ability of the three kinds of glues, three cores with both ends plugged by different glues are placed at $250{ }^{\circ} \mathrm{C}$ for 5 days. Figure 10 shows the comparison of the three kinds of glues before and after heating.
From this figure, we can see that CPS copper oxide yields the best performance. After a long time of heating, the plugging ability is still well-kept. On the contrary, the other two kinds of glues show different levels of melting or deformation. Therefore, CPS copper oxide is chosen as the experimental glue to plug the ends of the core.

Two groups of experiments are done to investigate the influence of ends plugging on imbibition recovery. The first group uses core sample labeled A-1 and oil sample labeled S1 to accomplish the experiment. The water injection rate and width of the mesh are $0.05 \mathrm{ml} / \mathrm{min}$ and $1 \mathrm{~cm}$, respectively. The imbibition recovery is tested under three different temperatures including 21, 60 and $90{ }^{\circ} \mathrm{C}$. Combing with the results of core labeled A-3, the comparisons of imbibition recoveries and recovery rates with and without plugging are shown in Fig. 11. From this figure, we can see that for A-3, the injected water can only contact the matrix through the fracture created due to the plugging. Therefore, compared with the no-plugging case, the contact area is greatly reduced and the recovery by imbibition decreases accordingly. From the oil recovery rate curves, we can see that similar to the results of the first method, the difference only exists at the initial stage when imbibition occurs; after that, both curves show a trend to overlap.

The second group uses oil sample labeled S1 and core samples labeled A-11 and A-16 to accomplish the experiment. The environment temperature is set to $60^{\circ} \mathrm{C}$. The width of mesh is $1 \mathrm{~cm}$. The ends of A-16 are plugged by CPS copper oxide and then both cores are flooded by $250^{\circ}$ steam. Steam injection rate is $0.05 \mathrm{ml} / \mathrm{min}$ (water equivalent). Figure 12 shows the comparison of imbibition recovery and oil recovery rate. From this figure, we can see that similar with hot water flooding, the ends plugging has a great influence on the development effect. After plugging, imbibition recovery decreases $11.32 \%$ due to the 


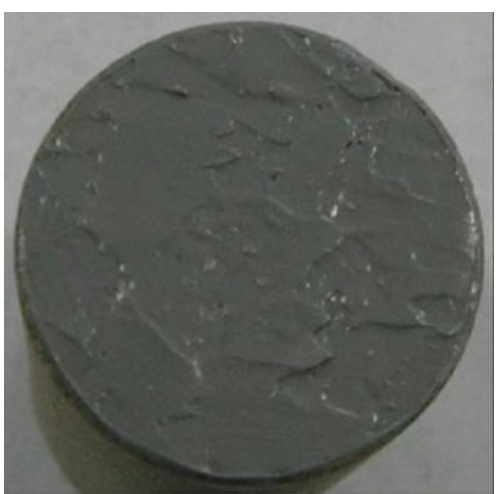

Common glue (before)

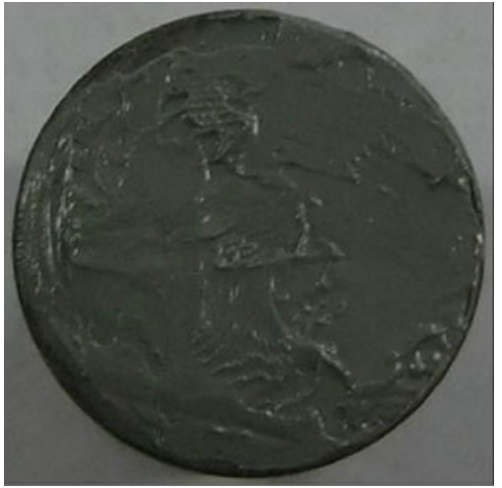

Common glue (after)

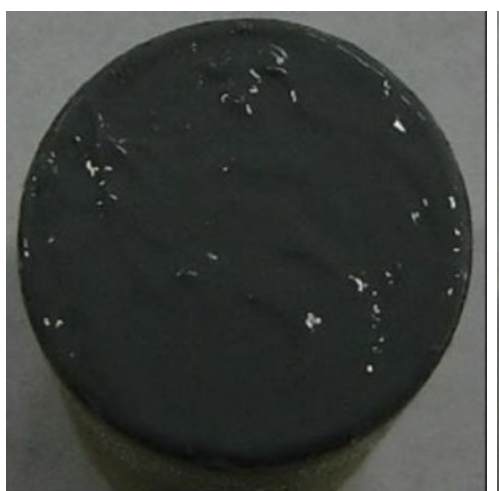

Silicone sealant (before)

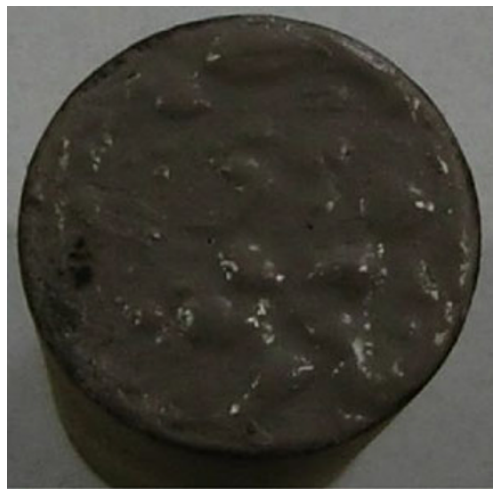

Silicone sealant (after)

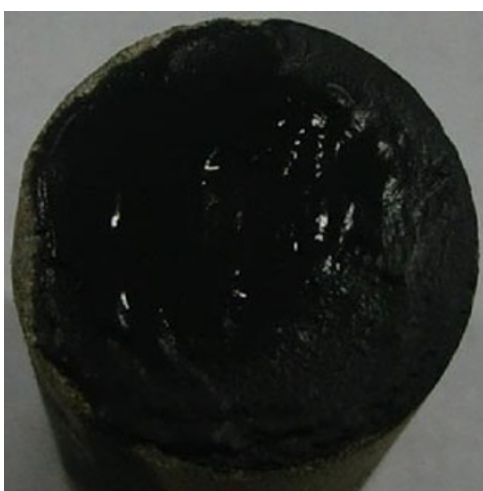

CPS copper oxide (before)

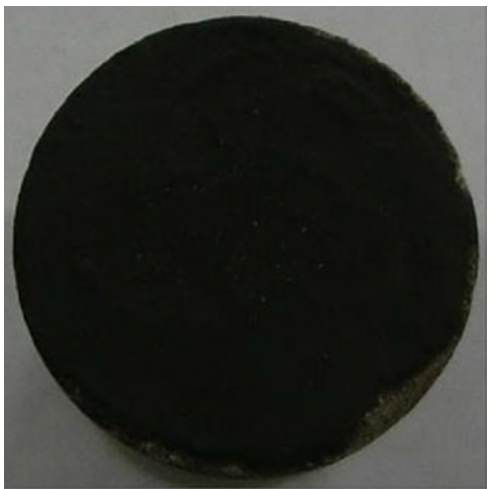

CPS copper oxide (after)

Fig. 10 Comparison of three kinds of glues before and after heating

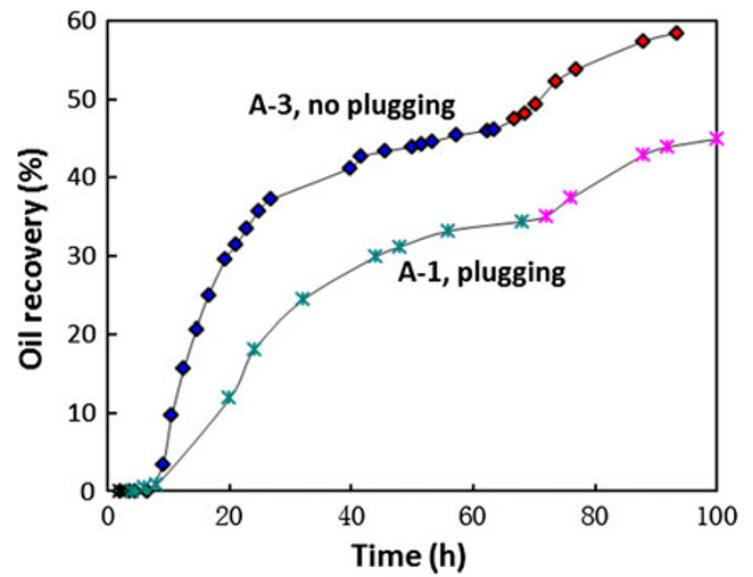

(a)

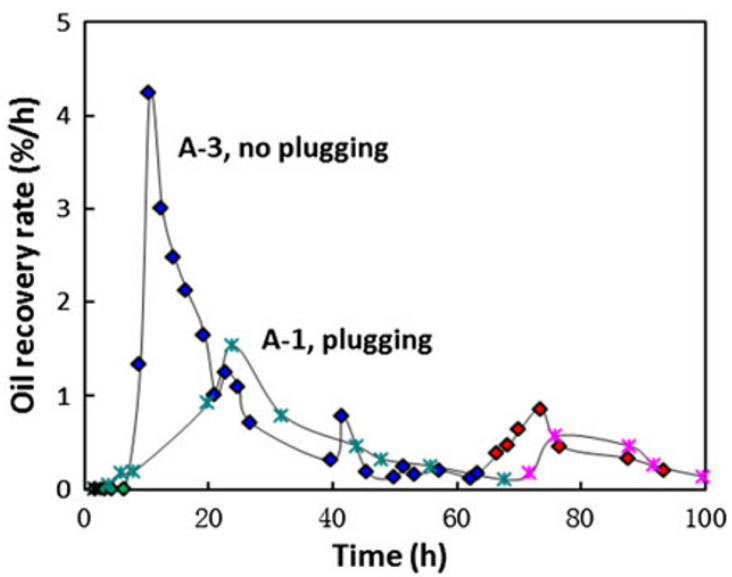

(b)

Fig. 11 Comparison of recoveries and recovery rates of cores with and without plugging: a recovery curves, b recovery rate curves

lowered oil production rate at the initial stage after imbibition starts to occur.

From the above experiments, we can conclude that the development degree of fractures exerts great influence on the development effect of fractured heavy oil reservoir. The bigger the development degree is, the larger the contact area and then the better the performance for both hot water flooding and steam flooding will be.
Influence of matrix permeability on imbibition recovery

Oil sample labeled S1 and low permeability core labeled A-6 are used to accomplish the experiment. The dynamic imbibition of the core is tested at 21,60 and $90{ }^{\circ} \mathrm{C}$ successively. Water injection rate and width of the mesh are $0.05 \mathrm{ml} / \mathrm{min}$ and $1 \mathrm{~cm}$, respectively. The comparisons of recoveries and oil recovery rates of the low and high 


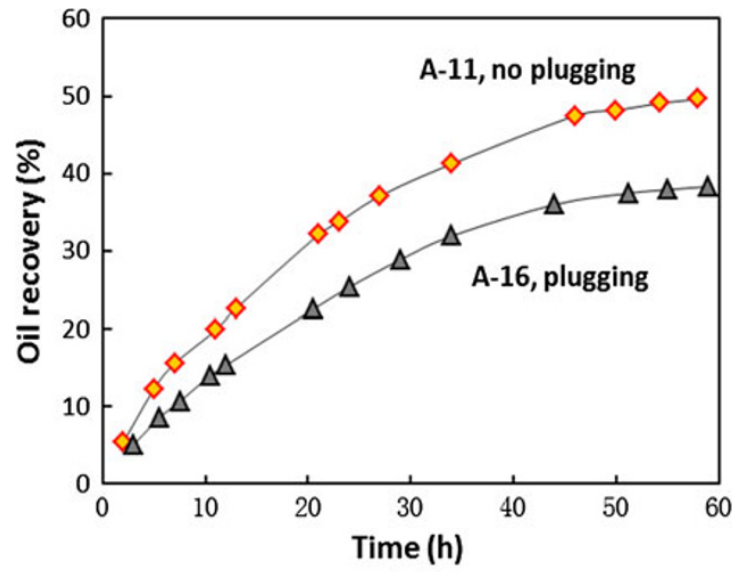

(a)

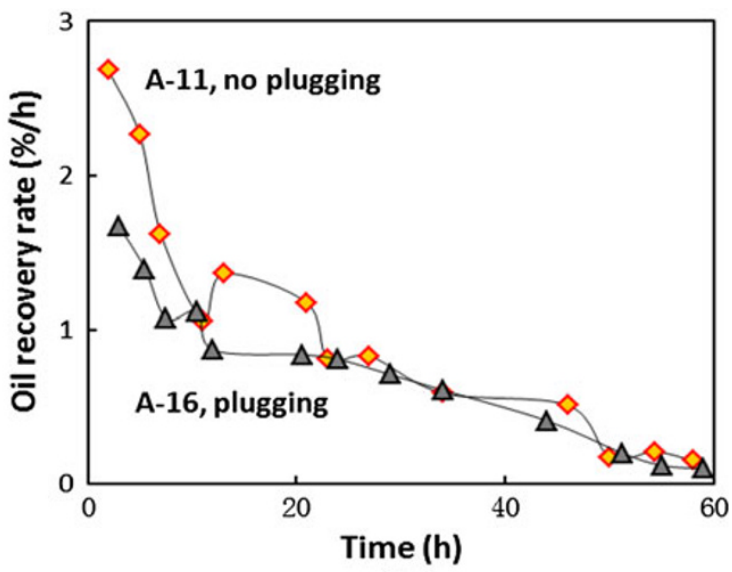

(b)

Fig. 12 Comparison of recoveries and recovery rates of cores with and without plugging (steam flooding): a recovery curves, $\mathbf{b}$ recovery rate curves

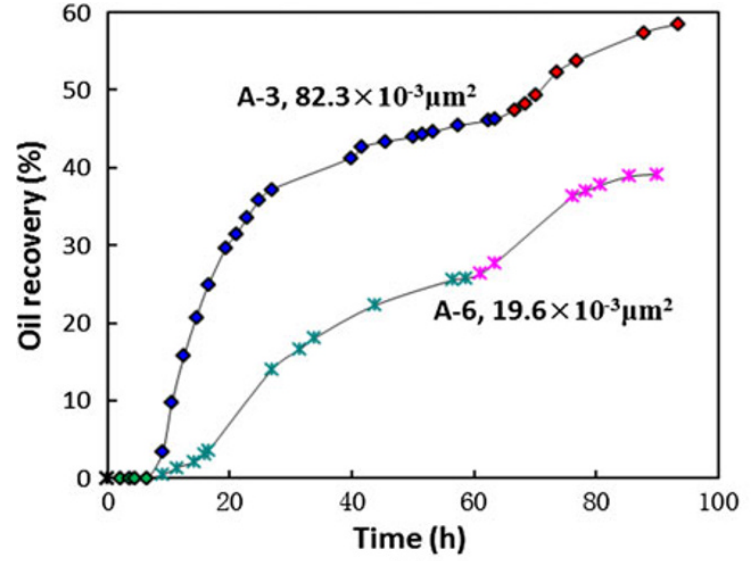

(a)

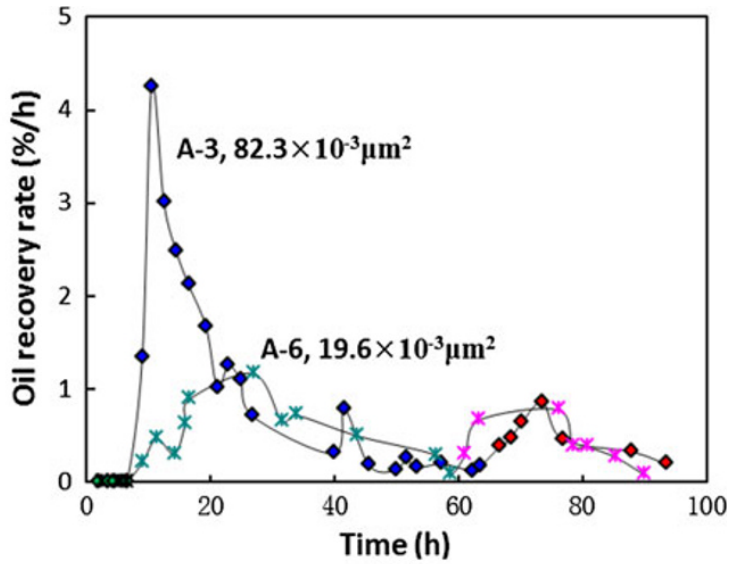

(b)

Fig. 13 Comparison of recoveries and recovery rates of cores with different matrix permeabilities: a recovery curves, b recovery rate curves

permeability cores are shown in Fig. 13. As shown in this figure, imbibition does not occur at $21^{\circ} \mathrm{C}$ for both cores. When the temperature is increased to $60{ }^{\circ} \mathrm{C}$, imbibition begins to occur and oil recovery of the high permeability core increases to $46.22 \%$, which is $20.52 \%$ higher than that of low permeability core. When the temperature is increased to $90{ }^{\circ} \mathrm{C}$, the final imbibition recovery of the two cores is 58.51 and $39.16 \%$, respectively.

For high permeability cores, water can penetrate into the core and displace oil out under a smaller capillary force compared with low permeability cores. This is the advantage of high permeability. However, from another aspect, an average microscopic pore radius of the core can be defined which is proportional to the square root of permeability over porosity (Ma and Zhang 1999; Leverett 1939). So according to the parameters of the cores shown in Table 3, high permeability cores have larger pore radius compared with lower permeability cores.

Therefore, along with the increase of permeability, the average radius of the pore increases and the capillary force decreases accordingly. This is the disadvantage of high permeability. The final imbibition effect is affected by these two aspects at the same time. In our experiments, only two kinds of cores are available and the high permeability core yields the better performance.

Influence of oil viscosity on imbibition recovery

Oil samples labeled S2 and S3 and cores labeled A-2 and A-5 are used to accomplish the experiment. Water injection rate and width of the mesh are $0.05 \mathrm{ml} / \mathrm{min}$ and $1 \mathrm{~cm}$, respectively. Similar to the previous experiments, the imbibition performance of the cores are tested at 21,60 and 


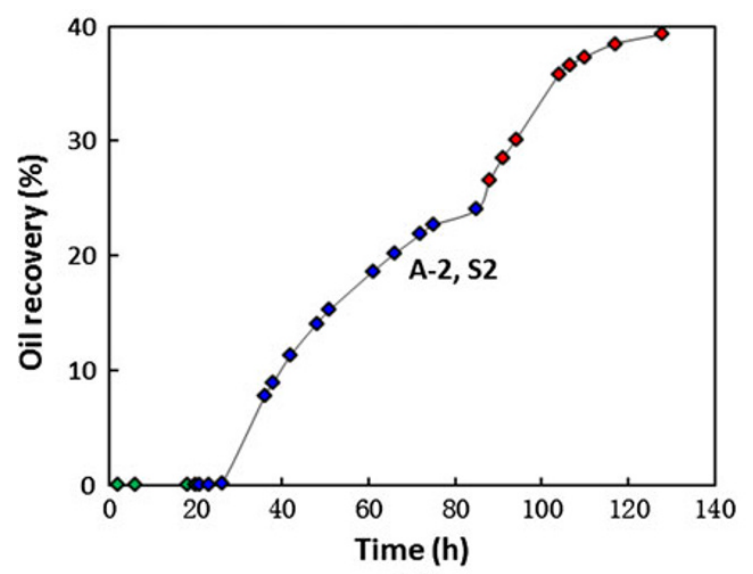

(a)

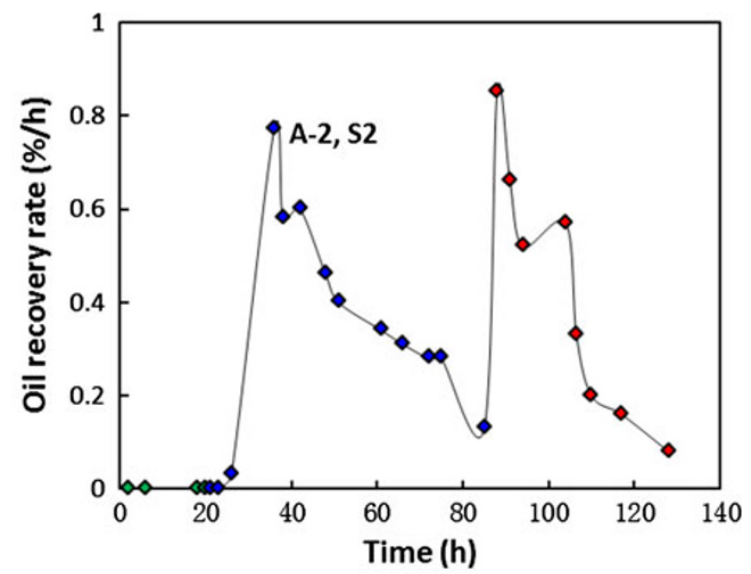

(b)

Fig. 14 Recovery and recovery rate of A-2 (saturated by S2): a recovery curve, b recovery rate curve

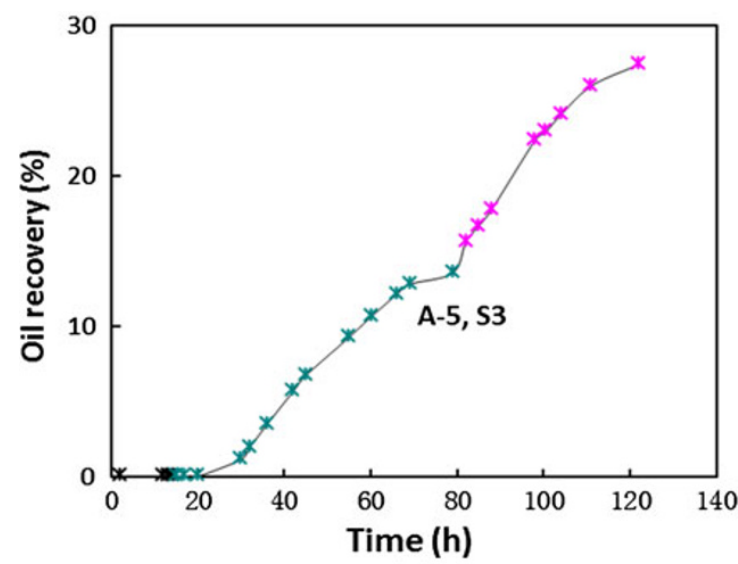

(a)

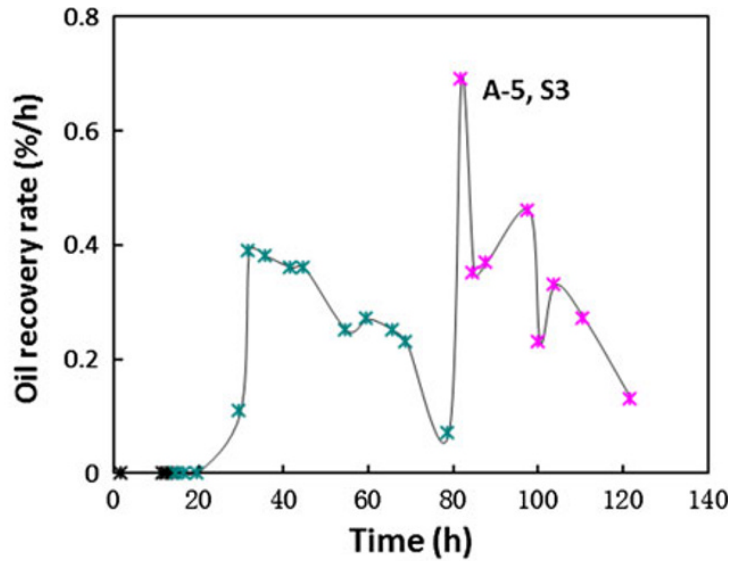

(b)

Fig. 15 Recovery and recovery rate of A-5 (saturated by S3): a recovery curve, b recovery rate curve

$90{ }^{\circ} \mathrm{C}$ successively. Figures 14 and 15 show the recoveries and oil recovery rates of $\mathrm{S} 2$ and $\mathrm{S} 3$, respectively. From Fig. 10, we can see that for S2, imbibition does not occur at $21^{\circ} \mathrm{C}$. When the temperature is increased to $60{ }^{\circ} \mathrm{C}$, oil recovery rate curve shows the first peak. The maximum oil recovery rate and recovery of this stage are $0.77 \% / \mathrm{h}$ and $24.00 \%$, respectively. When the temperature is increased to $90{ }^{\circ} \mathrm{C}$, oil recovery rate curve shows the second peak and the maximum oil rate reaches $0.85 \% / \mathrm{h}$ which is slightly higher than the former one. The final oil recovery of $\mathrm{S} 2$ is $39.3 \%$. From Fig. 15, we can see that S3 shows the same trend with $\mathrm{S} 2$. Stage recovery at $60{ }^{\circ} \mathrm{C}$ and the final recovery at $90{ }^{\circ} \mathrm{C}$ are 13.52 and $27.37 \%$, respectively. For oil recovery rate curve of $\mathrm{S} 3$, the second peak is 1.7 times of the first peak.

Figure 16 shows the comparison of oil recoveries for different oil samples at each stage. From this figure, we can see that the bigger the oil viscosity is, the smaller the stage

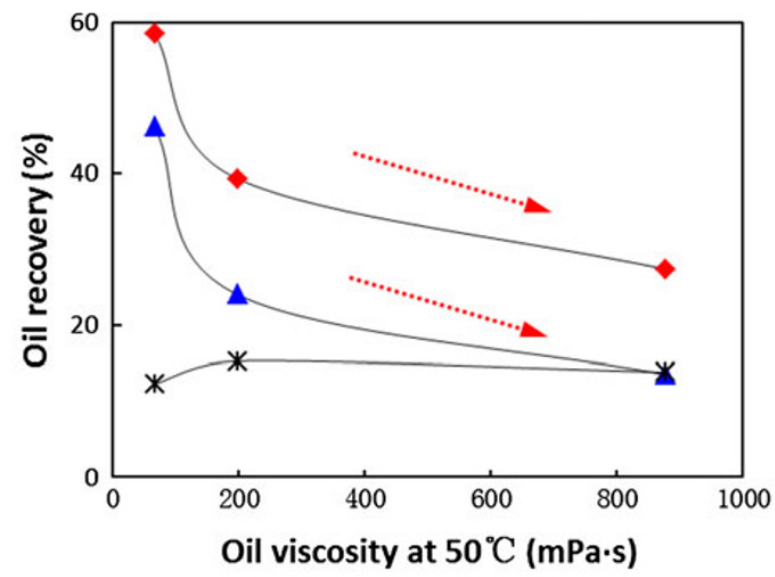

$₫$ Stage oil recovery at $60^{\circ} \mathrm{C}-$ - Stage oil recovery at $90^{\circ} \mathrm{C}$ $\neg$ Final oil recovery

Fig. 16 Relationship between imbibition recovery and oil viscosity 
oil recoveries at $60{ }^{\circ} \mathrm{C}$ and the final recoveries at $90{ }^{\circ} \mathrm{C}$ will be. This is because the viscous force increases correspondingly along with the increase of oil viscosity. However, due to low oil recoveries at $60^{\circ} \mathrm{C}$ for $\mathrm{S} 2$ and $\mathrm{S} 3$, when the temperature is increased to $90^{\circ} \mathrm{C}$, oil viscosity decreases significantly and more oil is recovered at this stage compared with S1. Therefore, we can conclude that high oil viscosity significantly decreases the imbibition recovery but it enjoys great potential of improving oil recovery for fractured heavy oil reservoir.

Influence of water injection rate on imbibition recovery

One advantage of dynamic imbibition experiment over static imbibition experiment is that the injected fluid or injection rate can be adjusted during the flooding process to investigate their influences on imbibition recovery. For this experiment, oil sample labeled $\mathrm{S} 1$ and Core samples labeled A-6, A-7, A-14 and A-15 are selected. For four cores, the water injection rates are set to $0.05,0.2,0.5$ and $2 \mathrm{ml} / \mathrm{min}$, respectively. The width of the mesh is $1 \mathrm{~cm}$ for all cores and all experiments are done at $60{ }^{\circ} \mathrm{C}$.

Figure 17 shows the comparison of imbibition recoveries and oil recovery rates for different cores. From this figure, we can see that the imbibition recovery increases at first and then decreases along with the increase of water injection rate. This is because when injection rate is too small, the oil recovered by imbibition is hard to be flooded out immediately, which will affect the final oil recovery to some extent. On the contrary, when injection rate is too high, the water in the fracture is flooded out by the following injected water before it enters into the matrix and displaces oil out. So, the final oil recovery is also affected. In our experiments, the dynamic imbibition yields the best oil recovery when water injection rate is $0.5 \mathrm{ml} / \mathrm{min}$.

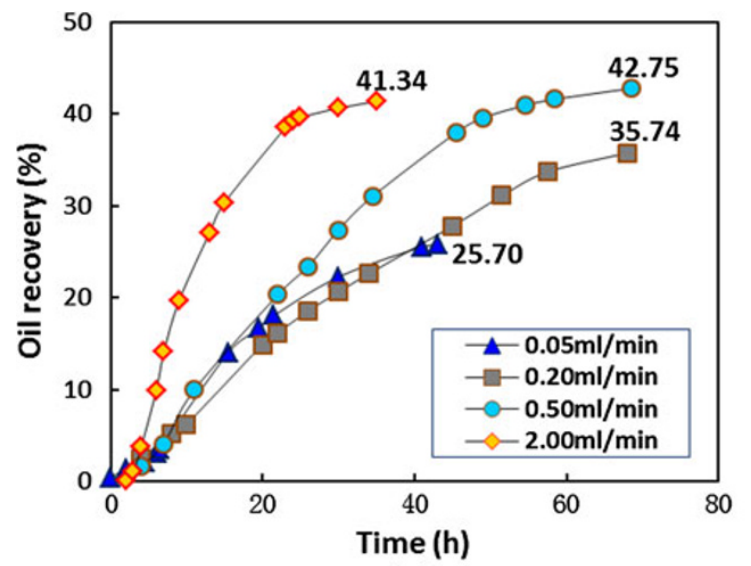

(a)
Influence of injected fluid on imbibition recovery

Oil samples labeled S1 and cores labeled A-10 and A-11 are used to accomplish the first group experiment. The two cores are flooded by $120^{\circ}$ hot water and $250^{\circ}$ steam, respectively. In order to decrease heat loss, the pipeline between steam generator and the core are wrapped by heating belt and the temperature of the heating belt is adjusted through temperature controller as needed. Fluid injection rate and the width of the mesh for both experiments are set to $0.05 \mathrm{ml} / \mathrm{min}$ and $1 \mathrm{~cm}$, respectively. The environment temperature is $60^{\circ} \mathrm{C}$. Figure 18 shows the comparison of imbibition recoveries and oil recovery rates. From this figure, we can see that the imbibition recoveries for hot water flooding and steam flooding are 45.71 and $49.61 \%$, respectively. Though the performance of steam flooding is better than hot water flooding, due to the low viscosity, the amplitude of the recovery improvement is limited.

Oil samples labeled S2 and cores labeled A-8 and A-9 are used to accomplish the second group experiment. The conditions and procedures are the same as the first group. Experimental results are shown in Fig. 19. As illustrated in this figure, the imbibition recoveries for hot water flooding and steam flooding are 30.59 and $37.98 \%$, respectively. Steam flooding gains a better performance than hot water flooding does. This is because on one hand, the temperature of the steam is much higher than that of hot water. Therefore, more oil is recovered by imbibition due to low oil viscosity. On the other hand, compared with hot water flooding, it is easier for steam to penetrate into the small pores and displace oil in these pores out.

Finally, oil samples labeled S3 and cores labeled A-12 and A-13 are used to accomplish the third group experiment. The conditions and procedures are the same as the first two group experiments. Experimental results are shown in Fig. 20. From this figure, we can see that the

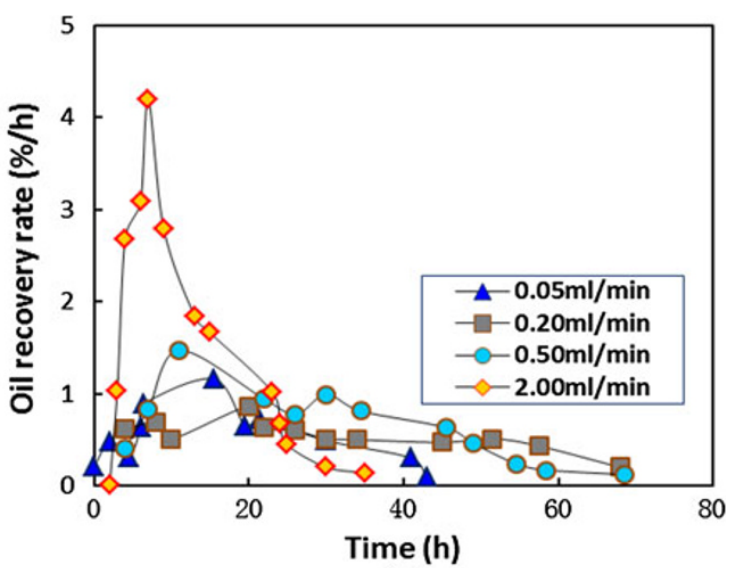

(b)

Fig. 17 Recovery and recovery rate of A-5 (saturated by S3): a recovery curve, b recovery rate curve 


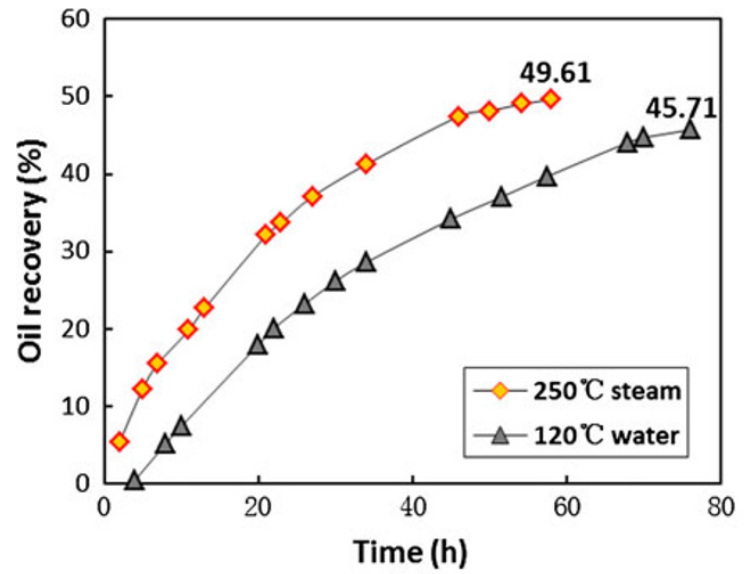

(a)

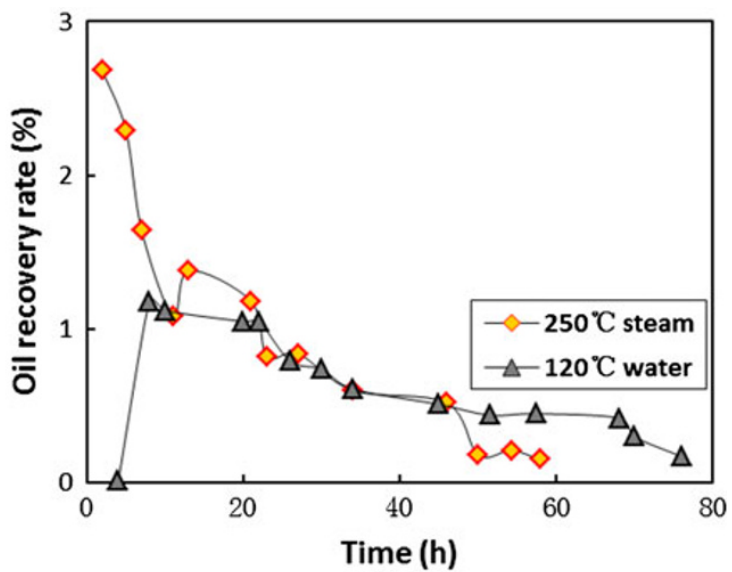

(b)

Fig. 18 Comparison of recoveries and recovery rates of hot-water flooding and steam flooding (A-10 and A-11): a recovery curves, b recovery rate curves

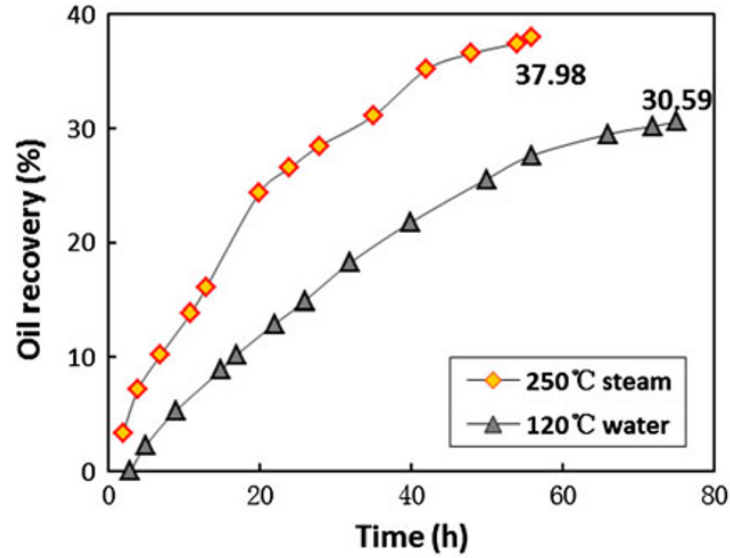

(a)

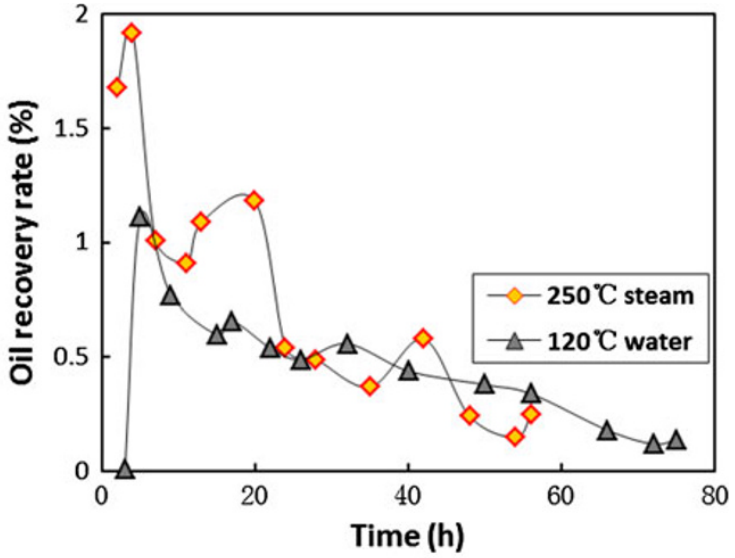

(b)

Fig. 19 Comparison of recoveries and recovery rates of hot water flooding and steam flooding (A-8 and A-9): a recovery curves, b recovery rate curves

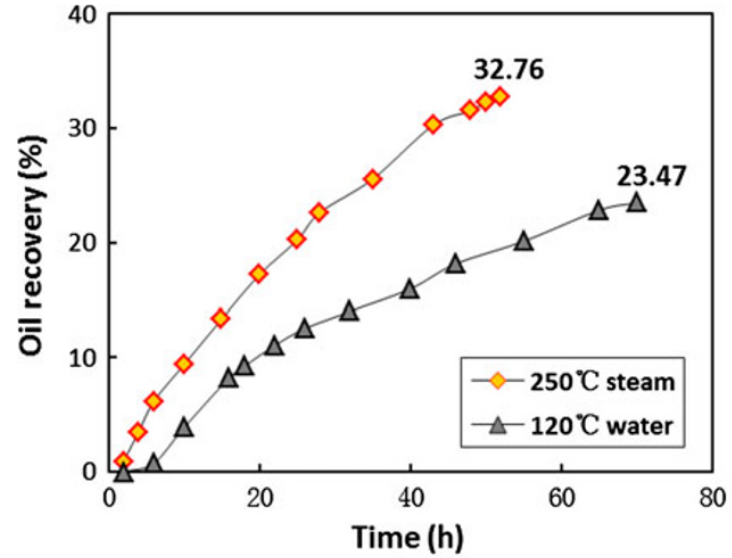

(a)

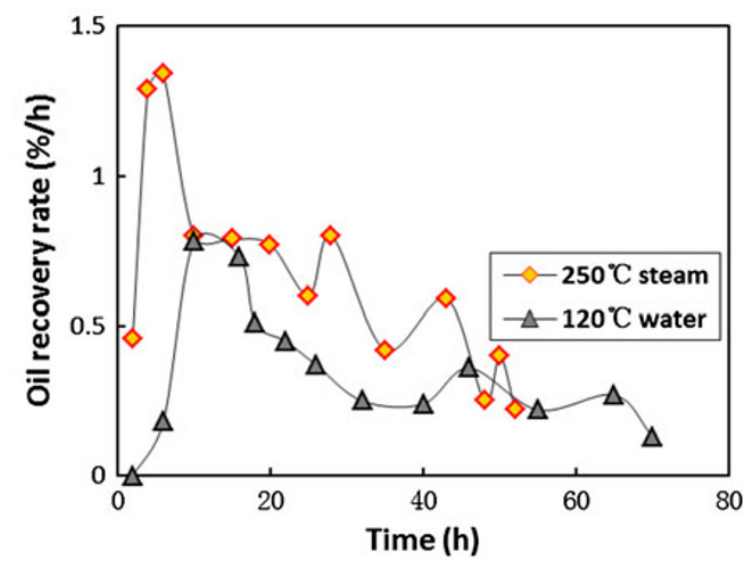

(b)

Fig. 20 Comparison of recoveries and recovery rates of hot water flooding and steam flooding (A-12 and A-13): a recovery curves, b recovery rate curves 


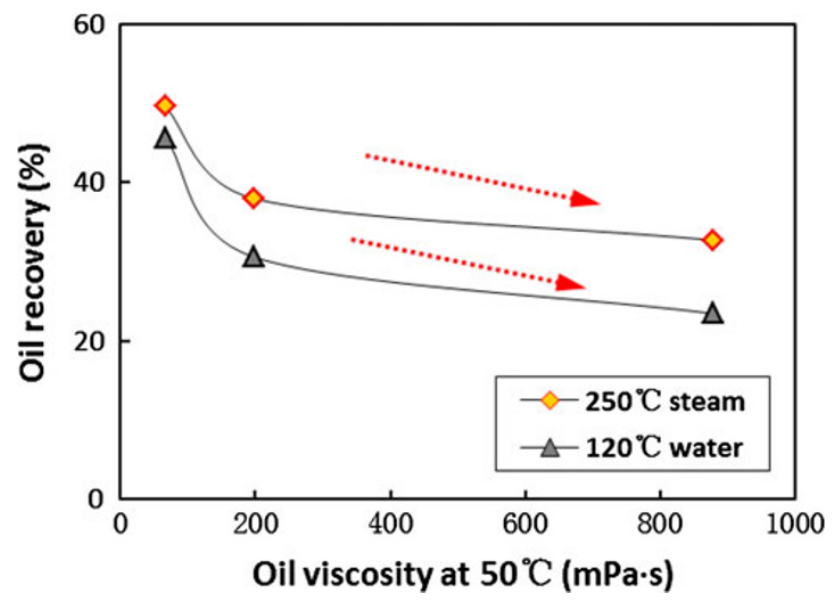

Fig. 21 Relationship between imbibition recovery and oil viscosity

imbibition recoveries for hot water flooding and steam flooding are 23.47 and $32.76 \%$, respectively. Due to high viscosity of S3, oil recoveries for both methods are smaller than those of the first two groups.

Figure 21 shows the relationship between oil viscosity and imbibition recovery according to the three group experiments. From this figure, we can see that recoveries of both hot water flooding and steam flooding decrease accordingly along with the increase of viscosity. However, from another aspect, high viscosity oil enjoys great potential of improving oil recovery due to the low recovery when it is flooded by low temperature fluid. As shown in Fig. 21, S3 gets the biggest recovery gap between the two kinds of flooding patterns.

Influence of wettability on imbibition recovery

The oil sample labeled S1 and the cores labeled A-3 (waterwet) and B-1 (oil-wet) are used to accomplish the experiment. Fluid injection rate and the width of the mesh are set to $0.05 \mathrm{ml} / \mathrm{min}$ and $1 \mathrm{~cm}$, respectively. Similar to the previous experiments, the imbibition performance of the cores is tested at 21,60 and $90{ }^{\circ} \mathrm{C}$ successively. Figure 22 shows the comparison of recoveries and oil recovery rates of A-3 and B-1. From this figure, we can see that for oil-wet core B-1, nearly no oil is produced. This is because for water-wet core, water penetrates into the core and displaces oil out under capillary force. However, for oil-wet core, capillary force is the resistance to this process. So, if no measures are taken (for e.g., surfactant injection to alter wettability), imbibition is hardly to happen for oil-wet cores.

\section{Conclusions}

(1) Imbibition recovery is proportional to the contact area of matrix and fractures. The larger the contact area is, the higher the recovery will be. Therefore, for fractured heavy oil reservoir, the development degree of fractures has great influence on the imbibition recovery.

(2) Under the same capillary force, high permeability core has lower resistance the oil in high permeability core flows easily when compared with that in low permeability core. However, high permeability cores often have larger average radius the capillary force is lower than that in low permeability cores. Limited to the availability of cores, only two kinds of cores are tested and the core with higher matrix permeability yields the better performance.

(3) The viscous force increases along with the increase of oil viscosity. So, at the same temperature, the lower the viscosity is, the higher the imbibition recovery

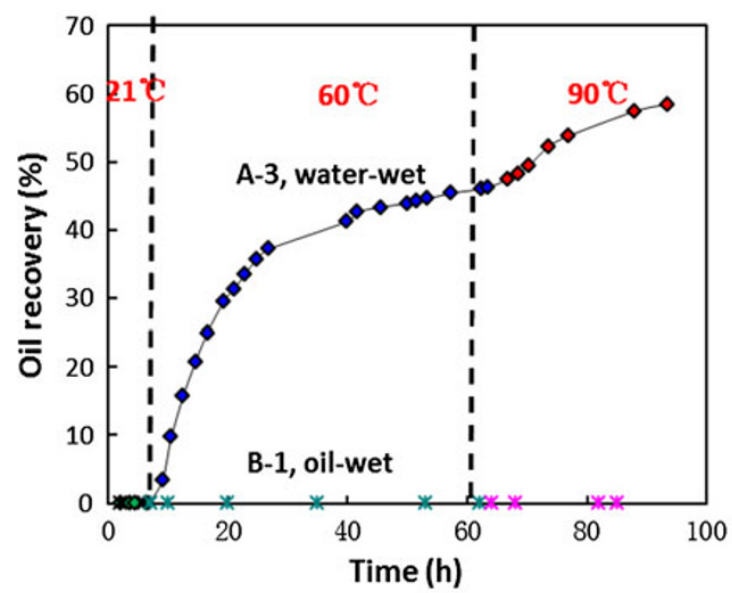

(a)

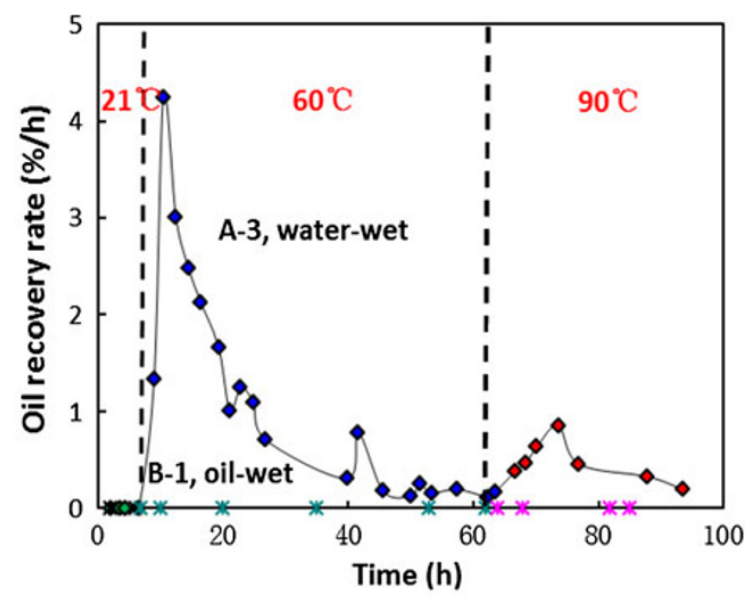

(b)

Fig. 22 Comparison of recoveries and recovery rates of different wettability cores: a recovery curves, $\mathbf{b}$ recovery rate curves 
will be. However, due to the low recovery, high viscosity oil enjoys great potential of improving oil recovery if thermal methods are applied.

(4) The fluid injection rate also affects the imbibition recovery to some extent. When injection rate is too small, the oil recovered by imbibition is hard to be flooded out immediately. On the contrary, when injection rate is too high, the water in the fracture is flooded out before it enters into the matrix and displaces oil out. So, an optimal fluid injection rate exists. For experiments illustrated in this paper, the optimal fluid injection rate is $0.5 \mathrm{ml} / \mathrm{min}$.

(5) For same oil, steam flooding yields better performance than hot water flooding. The higher the oil viscosity is, the larger the gap between the two development styles will be. Therefore, for fractured reservoir with crude oils or tars, high-temperature steam flooding can significantly reduce the oil viscosity and enhance the imbibition recovery.

(6) For water-wet core, water penetrates into the core and displaces oil out under capillary force. However, for oil-wet core, capillary force is the resistance to this process. In our experiment, for oil-wet core, imbibition does not occur and nearly no oil is produced.

Acknowledgments This work was financially supported by National Science Foundation (No. 51274212) and Science Foundation of China University of Petroleum, Beijing (No. YJRC-2013-05).

Open Access This article is distributed under the terms of the Creative Commons Attribution License which permits any use, distribution, and reproduction in any medium, provided the original author(s) and the source are credited.

\section{Appendix}

See Tables 4 and 5

Table 4 Oil recoveries of cores: water flooding

No. Oil sample Oil recovery at the end of each temperature (\%)

\begin{tabular}{lllll}
\cline { 3 - 5 } & & $30{ }^{\circ} \mathrm{C}$ & $60{ }^{\circ} \mathrm{C}$ & $90{ }^{\circ} \mathrm{C}$ \\
\hline A-1 & S1 & 0 & 34.40 & 44.96 \\
A-2 & S2 & 0 & 24.00 & 39.30 \\
A-3 & S1 & 0 & 46.22 & 58.51 \\
A-4 & S1 & 0 & 56.30 & 69.60 \\
A-5 & S3 & 0 & 13.52 & 27.37 \\
A-6 & S1 & 0 & 25.70 & 39.16 \\
A-7 & S1 & 0 & 35.74 & - \\
A-14 & S1 & 0 & 42.75 & - \\
A-15 & S1 & 0 & 41.34 & - \\
B-1 & S1 & 0 & 0 & 0 \\
\hline
\end{tabular}

Table 5 Oil recoveries of cores: hot water or steam flooding

\begin{tabular}{llll}
\hline No. & Oil sample & Oil recovery $(\%)$ & \\
\cline { 3 - 4 } & & $120^{\circ} \mathrm{C}$ hot water flooding & $250^{\circ} \mathrm{C}$ steam flooding \\
\hline A-8 & S2 & 30.59 & - \\
A-9 & S2 & - & 37.98 \\
A-10 & S1 & 45.71 & - \\
A-11 & S1 & - & 49.61 \\
A-12 & S3 & 23.47 & - \\
A-13 & S3 & - & 32.76 \\
A-16 & S1 & - & 38.29 \\
\hline
\end{tabular}

\section{References}

Bernard CS, Jerome JF (1982) Steam-drive pilot in a fractured carbonated reservoir: Lacq Superieur field. J Pet Technol $34: 873-880$

Jishan L (2006) The effect of surfactant system on imbibition behavior. Ph.D. Dissertation, Institute of porous flow and fluid mechanics of CAS, Tianjin

Leverett MC (1939) Flow of oil-water mixtures through unconsolidated sands. Trans AIME 133:149-171

Lin Y, Wang MB, Lei P (2000) Application of horizontal well in developing Caogu 1 buried-hill fractured heavy oil reservoir. Spec Oil Gas Reserv 7:24-26

Ma SM, Zhang X (1999) Characterization of wettability from spontaneous imbibition measurements. JCPT 38:1-8

Mattax CC, Kyte JR (1962) Imbibition oil recovery from fractured, water-drive reservoir. SPE J 2:177-184

Mehran PD, Abbas F (2000) Cocurrent and countercurrent imbibition in a water-wet matrix block. SPE J 5:3-11

Mollaei A, Maini B (2010) Steam flooding of naturally fractured reservoirs: basic concepts and recovery mechanisms. J Can Pet Technol 49:65-70

Penney R, Moosa R, Shahin G, Hadhrami F, Kok A, Engen G, Ravesteijn OV, Rawnsley K, Kharusi B (2005) Steam injection in fractured carbonate reservoirs: starting a new trend in EOR. Paper (SPE 10727) presented at the international petroleum technology conference, Doha, 21-23 November 2005

Rangel-German ER, Kovscek AR (2002) Experimental and analytical study of multidimensional imbibition in fractured porous media. J Pet Sci Eng 36:45-60

Sumnu MD (1996) A study of steam injection in fractured media. Dissertation, Stanford University, Stanford

Sumnu MD, Aziz K (1996) An experimental and numerical study on steam injection in fractured systems. Paper (SPE 35459) presented at the SPE/DOE improved oil recovery symposium, Tulsa, 21-24 April 1996

Wang YZ, Yuan SY, Song XM, Ran QQ, Su Y (2004) Recovery mechanism simulation for the fractured igneous heavy oil reservoir of the Block Zao 35, Dagang oilfield. Pet Explor Dev 31(105): 107

Yuan SY, Ran QQ, Hu YL, Ren BS, Wang YZ (2005) Effective method for development of igneous fractured heavy oil reservoir. Acta Pet Sinica 26:63-68 